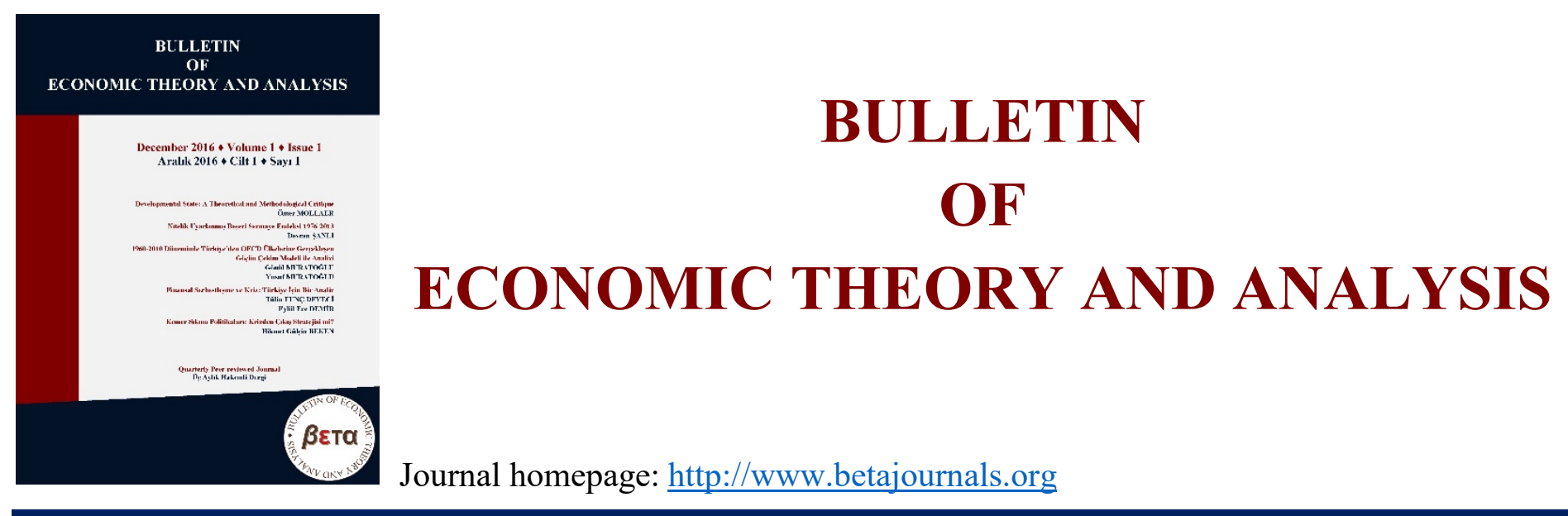

\title{
Global Business Cycles in a Neoclassical Growth Model with Spirits of Capitalism
}

Wei-Bin ZHANG $\odot$ https://orcid.org/0000-0002-3012-304X

To cite this article: Zhang, W. B. (2019) Global Business Cycles in a Neoclassical Growth Model with Spirits of Capitalism. Bulletin of Economic Theory and Analysis, 4(1), 13-33.

Received: 3 May 2018

Accepted: 21 Jun 2019

Published online: 30 Jun 2019

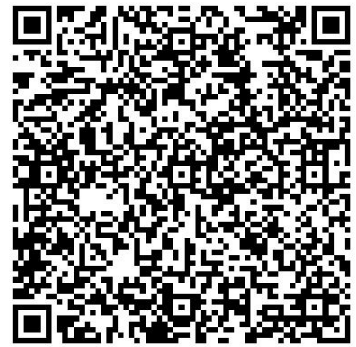

CAll right reserved 


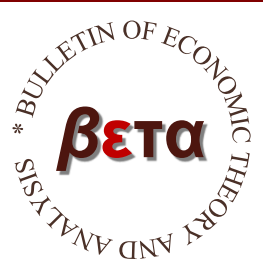

\title{
Bulletin of Economic Theory and Analysis
}

Volume IV, Issue 1, pp. 13-33, 2019

http://www.betajournals.org

Original Article / Araştırma Makalesi

Received / Alınma: 03.05.2018 Accepted / Kabul: 21.06.2019

\section{Global Business Cycles in a Neoclassical Growth Model with Spirits of Capitalism}

\author{
Wei-Bin Zhang ${ }^{\mathrm{a}}$ \\ ${ }^{a}$ Prof. Ph.D., Ritsumeikan Asia Pacific University, JAPAN ๑ https://orcid.org/0000-0002-3012-304X
}

\begin{abstract}
The purpose of the paper is to identify business cycles due to exogenous shocks in a global economic growth model with endogenous social status, endogenous preferences, and wealth accumulation. The basic model by Zhang (2017) is built on the basis of the Solow model, the Uzawa two-sector model, the Oniki-Uzawa trade model, and some ideas in the literature of economic growth with endogenous growth. The paper introduces various time-dependent exogenous shocks to Zhang's model. We show the existence of business cycles with different exogenous periodic shocks. Our comparative dynamic analysis shows, for instance, how exogenous changes in the propensities lead to global business cycles and oscillations in global income and wealth distribution. The unique contribution is to identify real business cycles in the neoclassical growth model with endogenous preference built on microeconomic foundation.
\end{abstract}

Anahtar Kelimeler Business Cycles, Exogenous Periodic Shocks, Social Status, Spirit of Capitalism, Global Income Inequality

JEL Kodu E210; E320; O410

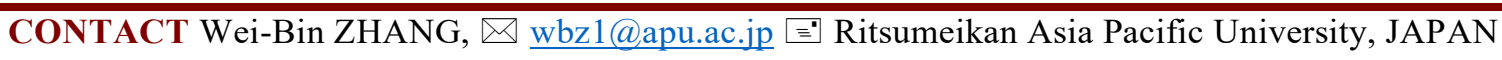




\section{Introduction}

It is well known that in The Theory of the Leisure Class Veblen (1899) examined economic consequences of conspicuous consumption and social status. Since then some other researchers considered conspicuous consumption, social status and spirit of capitalism as important determinants of economic development (e.g., Duesenberry, 1949; Frank, 1985; 2001; Rege, 2008). There are also formal models on economic growth and social status (e.g., Cole, Mailath, \& Postlewaite, 1992; Konrad, 1992; Fershtman, Murphy, \& Weiss, 1996; Rauscher, 1997). Nevertheless, except in a few papers issues related to dynamic interdependence between social status are examined in formal economic growth theory with international trade. Zhang (2017) makes a contribution to the literature by explicitly introducing social status into formal trade theory. Zhang's model deals with not only interactions between inequalities in income, wealth and economic structures between countries, but also introduces dynamics of preferences and social status into the formal trade theory. It is influenced by traditional neoclassical growth theory (Solow, 1956; Uzawa, 1961; Oniki \& Uzawa, 1965) and some ideas about modelling preferences changes and social status (Kurz, 1968; Chang, 2006; Corneo \& Jeanne, 2001; Clemens, 2004; Fisher \& Hof, 2005; Chen \& Guo, 2011).

There is a vast literature on endogenous and exogenous business cycles in theoretical economics (Zhang, 1991, 2005, 2006; Lorenz, 1993; Chiarella \& Flaschel, 2000; Shone, 2002; Gandolfo, 2005; Puu, 2011). Nevertheless, one can find only a few formal economic models with interactions between endogenous wealth, endogenous preference, income and wealth distribution between nations built with microeconomic foundation. This study makes a contribution to the literature of business cycles in a model built with microeconomic foundation. This paper extends Zhang's global economic growth model with endogenous social status, endogenous preferences, and wealth accumulation by allowing all constant parameters to be time-dependent parameters (Zhang, 2017). The paper is organized as follows. Section 2 introduces time-dependent exogenous changes into Zhang's model. In section 3 we examine the model's dynamic properties. Section 4 carries out comparative dynamic analysis. Section 5 concludes the study.

\section{The Global Growth Model with Free Trade and Endogenous Social Status}

This section makes Zhang's model (2017) more robust by making time-independent parameters to be time-dependent. The extended model explains movement of the system with different time-dependent shocks. As it only changes the constant parameters in Zhang's model, this section 
simply explains with further referring to Zhang's model. The world economy consists of different national economies, indexed by $j=1, \ldots, J$. The model applies Uzawa's analytical framework for national economy (Uzawa, 1961) to multination economies with free trade (Oniki \& Uzawa, 1965). National economies produce a homogenous capital good (Ikeda \& Ono, 1992). In addition to one capital sector, each national economy has one consumer good sector, supplying goods and services for domestic consumers. Assets are privately owned. Households' disposable incomes are used up consuming and saving. Input factors, capital and labor, are fully utilized. Markets are perfectly competitive. All prices are measured in terms of capital good and the price of capital good is unit. We introduce following variables:

subscript indices $i$ and $s$ - capital goods sector and consumer goods sector, respectively; $w_{j}(t)$ - wage rate per unit of human capital and per unit of time in country $j$;

$r(t)$ - rate of interest in global markets;

$p_{j}(t)$ - price of consumer goods in country $j$;

$K_{j}(t)$ and $\bar{K}_{j}(t)$ - total capital stock employed by and total value of wealth owned by country $j$

$c_{j}(t)$ and $\bar{k}_{j}(t)$ - consumption level of consumer goods and wealth owned by the representative household in country $j$;

$T_{j}(t)$ and $\bar{T}_{j}(t)$ - work hours and leisure hours of the representative household in country $j$;

$N_{j}(t)$ and $K_{j}(t)$ - total labor force of and capital stocks employed by country $j$;

$N_{j m}(t)$ and $K_{j m}(t)$ - labor force and capital stocks employed by sector $m$ in country $j$;

$F_{j m}(t)$ - output level of sector $m$ in country $j$;

$h_{j}(t)$ and $\delta_{j k}(t)$ - exogenous human capital and depreciation rate of physical capital in country $j$.

\section{National total labor supply}

A country's total labor supply is defined as follows: 


$$
N_{j}(t)=h_{j}(t) T_{j}(t) \bar{N}_{j}
$$

\section{Capital good sectors}

Capital good sectors' production functions are taken on the following Cobb-Douglass function form:

$$
\begin{aligned}
F_{j i}(t) & =A_{j i} K_{j i}^{\alpha_{j i}(t)}(t) N_{j i}^{\beta_{j i}(t)}(t), A_{j i}(t), \alpha_{j i}(t), \beta_{j i}(t) \\
> & 0, \alpha_{j i}(t)+\beta_{j i}(t)=1,
\end{aligned}
$$

where $A_{j i}(t), \alpha_{j i}(t)$, and $\beta_{j i}(t)$ are positive parameters. The marginal conditions imply:

$$
r(t)+\delta_{j k}(t)=\frac{\alpha_{j i}(t) F_{j i}(t)}{K_{j i}(t)}, w_{j}(t)=\frac{\beta_{j i}(t) F_{j i}(t)}{N_{j i}(t)}
$$

\section{Consumer good sectors}

Production functions are

$$
\begin{gathered}
F_{j s}(t)=A_{j s} K_{j s}^{\alpha_{j s}(t)}(t) N_{j s}^{\beta_{j s}(t)}(t), \alpha_{j s}(t)+\beta_{j s}(t)=1, \alpha_{j s}(t), \beta_{j s}(t) \\
>0
\end{gathered}
$$

where $A_{j s}(t), \alpha_{j s}(t)$, and $\beta_{j s}(t)$ are parameters. The marginal conditions are

$$
r(t)+\delta_{k j}(t)=\frac{\alpha_{j s}(t) p_{j}(t) F_{j s}(t)}{K_{j s}(t)}, w_{j}(t)=\frac{\beta_{j s}(t) p_{j}(t) F_{j s}(t)}{N_{j s}(t)}
$$

\section{Current income and disposable income}

Current income consists of interest payment $r(t) \bar{k}_{j}(t)$ and wage payment $h_{j}(t) T_{j}(t) w_{j}(t)$ as

$$
y_{j}(t)=r(t) \bar{k}_{j}(t)+h_{j}(t) T_{j}(t) w_{j}(t)
$$

Zhang's disposable income is the sum of the current disposable income and the value of wealth 


$$
\hat{y}_{j}(t)=y_{j}(t)+\bar{k}_{j}(t)
$$

\section{Budgets}

The disposable income is used up for saving $s_{j}(t)$ and consuming $p_{j}(t) c_{j}(t)$. The budget constraint means

$$
p_{j}(t) c_{j}(t)+s_{j}(t)=\hat{y}_{j}(t)
$$

The time-independent total available time $T_{0}$ is used up for leisure and work:

$$
T_{j}(t)+\bar{T}_{j}(t)=T_{0}
$$

From (9), (6), and (7) we have

$$
\hat{y}_{j}(t)=\bar{y}_{j}(t)-h_{j}(t) \bar{T}_{j}(t) w_{j}(t)
$$

in which

$$
\bar{y}_{j}(t) \equiv(1+r(t)) \bar{k}_{j}(t)+h_{j}(t) T_{0} w_{j}(t)
$$

Substitute (10) into (8)

$$
h_{j}(t) \bar{T}_{j}(t) w_{j}(t)+p_{j}(t) c_{j}(t)+s_{j}(t)=\bar{y}_{j}(t)
$$

\section{Utility functions}

The representative household decides $\bar{T}_{j}(t), c_{j}(t)$ and $s_{j}(t)$. Utility functions are taken on the following form

$$
U_{j}(t)=\bar{T}_{j}^{\sigma_{j 0}(t)}(t) c_{j}^{\xi_{j 0}(t)}(t) s_{j}^{\lambda_{j 0}(t)}(t), \sigma_{j 0}(t), \quad \xi_{j 0}(t), \lambda_{j 0}(t)>0,
$$

where $\sigma_{j 0}(t)$ is the propensity to use leisure time, $\xi_{j 0}(t)$ to consume consumer good, and $\lambda_{j 0}(t)$ to save. The propensities are time-dependent. 


\section{Relative wealth}

The average wealth of global economy is:

$$
\bar{k}(t)=\frac{1}{\bar{N}(t)} \sum_{j=1}^{J} \bar{k}_{j}(t) \bar{N}_{j}(t)
$$

Country $j^{\prime} s$ per household relative wealth $\tilde{k}_{j}(t)$ is:

$$
\tilde{k}_{j}(t)=\frac{\bar{k}_{j}(t)}{\bar{k}(t)}
$$

\section{National relative social status and propensities}

We consider national social status are positively related to national relative wealth. As in Zhang (2017), social status of the representative household is as follows:

$$
\omega_{j}(t)=\omega_{0 j}(t)+\omega_{k j}(t) \tilde{k}_{j}^{\omega_{j}}(t)
$$

where $\omega_{j}(t), \omega_{0 j}(t)$ and $\omega_{k j}(t)$ are positive parameters. It is assumed that the propensities to consume and to save are affected by social status as follows

$$
\begin{aligned}
& \sigma_{j 0}\left(\omega_{j}(t)\right)=\bar{\sigma}_{j 0}(t)+\tilde{\sigma}_{j 0}(t) \omega_{j}(t), \xi_{j 0}\left(\omega_{j}(t)\right) \\
& =\bar{\xi}_{j 0}(t)+\tilde{\xi}_{j 0}(t) \omega_{j}(t), \\
& \lambda_{j 0}\left(\omega_{j}(t)\right)=\bar{\lambda}_{j 0}(t)+\tilde{\lambda}_{j 0}(t) \omega_{j}(t),
\end{aligned}
$$

where $\bar{\sigma}_{j 0}(t), \bar{\xi}_{j 0}(t)$ and $\bar{\lambda}_{j 0}(t)$ are positive parameters, and $\tilde{\sigma}_{j 0}(t), \tilde{\xi}_{j 0}(t)$, and $\tilde{\lambda}_{j 0}(t)$ are parameters which may be either positive, zero, or negative.

\section{Optimal decisions by households}

The marginal conditions of maximizing the utility subject to the budget constrain means

$$
\begin{gathered}
h_{j}(t) w_{j}(t) \bar{T}_{j}(t)=\sigma_{j}(t) \bar{y}_{j}(t), p_{j}(t) c_{j}(t)=\xi_{j}(t) \bar{y}_{j}(t), s_{j}(t) \\
=\lambda_{j}(t) \bar{y}_{j}(t)
\end{gathered}
$$


where

$$
\begin{gathered}
\sigma_{j}(t) \equiv \rho_{j}(t) \sigma_{j 0}(t), \xi_{j}(t) \equiv \rho_{j}(t) \xi_{j 0}(t), \lambda_{j}(t) \equiv \rho_{j}(t) \lambda_{j 0}(t), \\
\rho_{j}(t) \equiv \frac{1}{\sigma_{j 0}(t)+\xi_{j 0}(t)+\lambda_{j 0}(t)}
\end{gathered}
$$

\section{Wealth accumulation}

The change in wealth is savings minus dissavings:

$$
\dot{\bar{k}}_{j}(t)=s_{j}(t)-\bar{k}_{j}(t) .
$$

\section{Full employment of resources}

Full employment of national resources implies

$$
K_{j i}(t)+K_{j s}(t)=K_{j}(t), \quad N_{j i}(t)+N_{j s}(t)=N_{j}(t)
$$

The total capital stocks employed by nations is the wealth owned by all households

$$
K(t)=\sum_{j=1}^{J} K_{j}(t)=\sum_{j=1}^{J} \bar{K}_{j}(t)=\sum_{j=1}^{J} \bar{k}_{j}(t) \bar{N}_{j}(t)
$$

\section{Demand and supply for consumer goods}

National market equilibrium for consumer good implies

$$
c_{j}(t) N_{j}(t)=F_{j s}(t), j=1, \ldots, J
$$

\section{Trade balances}

Global supply of capital good equals global net savings

$$
S(t)-K(t)+\sum_{j=1}^{J} \delta_{k j}(t) K_{j}(t)=F(t)
$$

in which 


$$
S(t) \equiv \sum_{j=1}^{J} s_{j}(t) \bar{N}_{j}(t), F(t) \equiv \sum_{j=1}^{J} F_{j i}(t)
$$

The change in global capital stock is the global capital output minus total depreciations of capital

$$
\dot{K}(t)=F(t)-\sum_{j=1}^{J} \delta_{k j}(t) K_{j}(t)
$$

Trade balances of national economies are

$$
B_{j}(t)=\left(\bar{K}_{j}(t)-K_{j}(t)\right) r(t)
$$

When $B_{j}(t)$ is positive (negative), country $j$ is in trade surplus (deficit). When $B_{j}(t)$ is zero, country $j$ 's trade is in balance.

\section{Global Economic Dynamics}

We built a multi-country model which is subject to different time-dependent exogenous shocks. This modelling framework is very robust as it allows us to analyze almost any types of exogenous changes. It should be emphasized that traditional theoretical trade models of heterogeneous households and multiple sectors fail to deal with this kind of complicated issues. It is often easier to develop an economic dynamic model than to solve it. This section shows how to compute the model. Before providing a computational procedure, we define a new variable:

$$
z_{1}(t) \equiv \frac{r(t)+\delta_{k 1}(t)}{w_{1}(t)}
$$

\section{Lemma}

The dynamics of the world economy is given by $J$ differential equations system with $J$ variables, $z_{1}(t),\left\{\tilde{k}_{j}(t)\right\}$, where $\left\{\tilde{k}_{j}(t)\right\} \equiv\left(\tilde{k}_{2}(t), \cdots, \tilde{k}_{J}(t)\right)$

$$
\begin{aligned}
& \dot{z}_{1}(t)=\Omega_{1}\left(z_{1}(t),\left\{\tilde{k}_{j}(t)\right\}, t\right), \\
& \dot{\tilde{k}}_{j}(t)=\Omega_{j}\left(z_{1}(t),\left\{\tilde{k}_{j}(t)\right\}, t\right), j=2, \ldots, J,
\end{aligned}
$$


where $\Omega_{j}$ are functions of $z_{1}(t),\left\{\tilde{k}_{j}(t)\right\}$ and $t$ defined in the Appendix. The other variables are determined as functions of $z_{1}(t),\left\{\tilde{k}_{j}(t)\right\}$ and $t \quad$ by: $z_{j}(t)$ by $(\mathrm{A} 3) \rightarrow r(t)$ and $w_{j}(t)$ by $(\mathrm{A} 2) \rightarrow \tilde{k}_{1}(t)$ by $(\mathrm{A} 17) \rightarrow \omega_{j}(t)$ by $(15) \rightarrow \sigma_{j 0}(t), \xi_{j 0}(t)$, and $\lambda_{j 0}(t)$ by $(16) \rightarrow \sigma_{j}(t)$, $\xi_{j}(t)$ and $\lambda_{j}(t)$ by $(16) \rightarrow K(t)$ by $(\mathrm{A} 20) \rightarrow \bar{k}(t)=K(t) / \bar{N} \rightarrow \bar{k}_{j}(t)$ by $(14) \rightarrow K_{j}(t)$ by $(\mathrm{A} 14) \rightarrow N_{j}(t)$ by $(\mathrm{A} 10) \rightarrow N_{j s}(t)$ by $(\mathrm{A} 7) \rightarrow N_{j i}(t)$ by (A11) $\rightarrow K_{j s}(t)$ and $K_{j i}(t)$ by $(\mathrm{A} 1) \rightarrow \bar{y}_{j}(t)$ by (A5) $\rightarrow F_{j i}(t)$ and $F_{j s}(t)$ by the definitions $\rightarrow p_{j}(t)$ by (A4) $\rightarrow \bar{T}_{j}(t)$, $c_{j}(t)$ and $s_{j}(t)$ by $(13) \rightarrow T_{j}(t)=T_{0}-\bar{T}_{j}(t)$.

The rest of this section summarizes the results in Zhang (2017) when all the parameters are constant. It is a special case of the model in this study. The simulation is for a3-country global economy. The parameters are taken on the following values:

$T_{0}=24$,

$$
\begin{aligned}
& \left(\begin{array}{l}
N_{1} \\
N_{2} \\
N_{3}
\end{array}\right)=\left(\begin{array}{l}
10 \\
20 \\
30
\end{array}\right),\left(\begin{array}{l}
h_{1} \\
h_{2} \\
h_{3}
\end{array}\right)=\left(\begin{array}{l}
6 \\
3 \\
1
\end{array}\right),\left(\begin{array}{l}
A_{1 i} \\
A_{2 i} \\
A_{3 i}
\end{array}\right)=\left(\begin{array}{c}
1.7 \\
1 \\
0.8
\end{array}\right),\left(\begin{array}{l}
A_{1 s} \\
A_{2 s} \\
A_{3 s}
\end{array}\right)=\left(\begin{array}{l}
1.5 \\
0.9 \\
0.7
\end{array}\right), \\
& \left(\begin{array}{l}
\alpha_{1 i} \\
\alpha_{2 i} \\
\alpha_{3 i}
\end{array}\right)=\left(\begin{array}{l}
0.31 \\
0.31 \\
0.31
\end{array}\right),\left(\begin{array}{l}
\alpha_{1 s} \\
\alpha_{2 s} \\
\alpha_{3 s}
\end{array}\right)=\left(\begin{array}{l}
0.33 \\
0.33 \\
0.33
\end{array}\right),\left(\begin{array}{l}
\omega_{1} \\
\omega_{2} \\
\omega_{3}
\end{array}\right)=\left(\begin{array}{l}
1 \\
1 \\
1
\end{array}\right),\left(\begin{array}{l}
\omega_{10} \\
\omega_{20} \\
\omega_{30}
\end{array}\right)=\left(\begin{array}{c}
0.15 \\
0.1 \\
0.05
\end{array}\right), \\
& \left(\begin{array}{l}
\omega_{1 \mathrm{k}} \\
\omega_{2 \mathrm{k}} \\
\omega_{3 \mathrm{k}}
\end{array}\right)=\left(\begin{array}{l}
1 \\
1 \\
1
\end{array}\right),\left(\begin{array}{l}
\bar{\lambda}_{10} \\
\bar{\lambda}_{20} \\
\vec{\lambda}_{30}
\end{array}\right)=\left(\begin{array}{l}
0.8 \\
0.7 \\
0.6
\end{array}\right),\left(\begin{array}{l}
\bar{\xi}_{10} \\
\bar{\xi}_{20} \\
\bar{\xi}_{30}
\end{array}\right)=\left(\begin{array}{l}
0.12 \\
0.12 \\
0.13
\end{array}\right),\left(\begin{array}{l}
\bar{\sigma}_{10} \\
\bar{\sigma}_{20} \\
\bar{\sigma}_{30}
\end{array}\right)=\left(\begin{array}{l}
0.15 \\
0.16 \\
0.17
\end{array}\right), \\
& \left(\begin{array}{l}
\tilde{\lambda}_{10} \\
\tilde{\lambda}_{20} \\
\tilde{\lambda}_{30}
\end{array}\right)=\left(\begin{array}{l}
0.1 \\
0.1 \\
0.1
\end{array}\right),\left(\begin{array}{l}
0.05 \\
\tilde{\xi}_{10} \\
\tilde{\xi}_{20} \\
\tilde{\xi}_{30}
\end{array}\right)=\left(\begin{array}{l}
0.05 \\
0.05 \\
0.05
\end{array}\right),\left(\begin{array}{l}
\tilde{\sigma}_{10} \\
\tilde{\sigma}_{20} \\
\tilde{\sigma}_{30}
\end{array}\right)=\left(\begin{array}{l}
0.05 \\
0.05 \\
0.05
\end{array}\right),\left(\begin{array}{l}
\delta_{1 k} \\
\delta_{2 k} \\
\delta_{3 k}
\end{array}\right)=\left(\begin{array}{l}
0.04 \\
0.04
\end{array}\right)
\end{aligned}
$$

The initial conditions are

$$
z_{1}(0)=0.04, \quad \tilde{k}_{2}(0)=0.95, \tilde{k}_{3}(0)=0.15
$$

The motion of the variables is plotted in Figure 1. In Figure 1, the global income is

$$
Y(t)=Y_{1}(t)+Y_{2}(t)+Y_{3}(t), Y_{j}(t)=F_{j i}(t)+p_{j}(t) F_{j s}(t),
$$



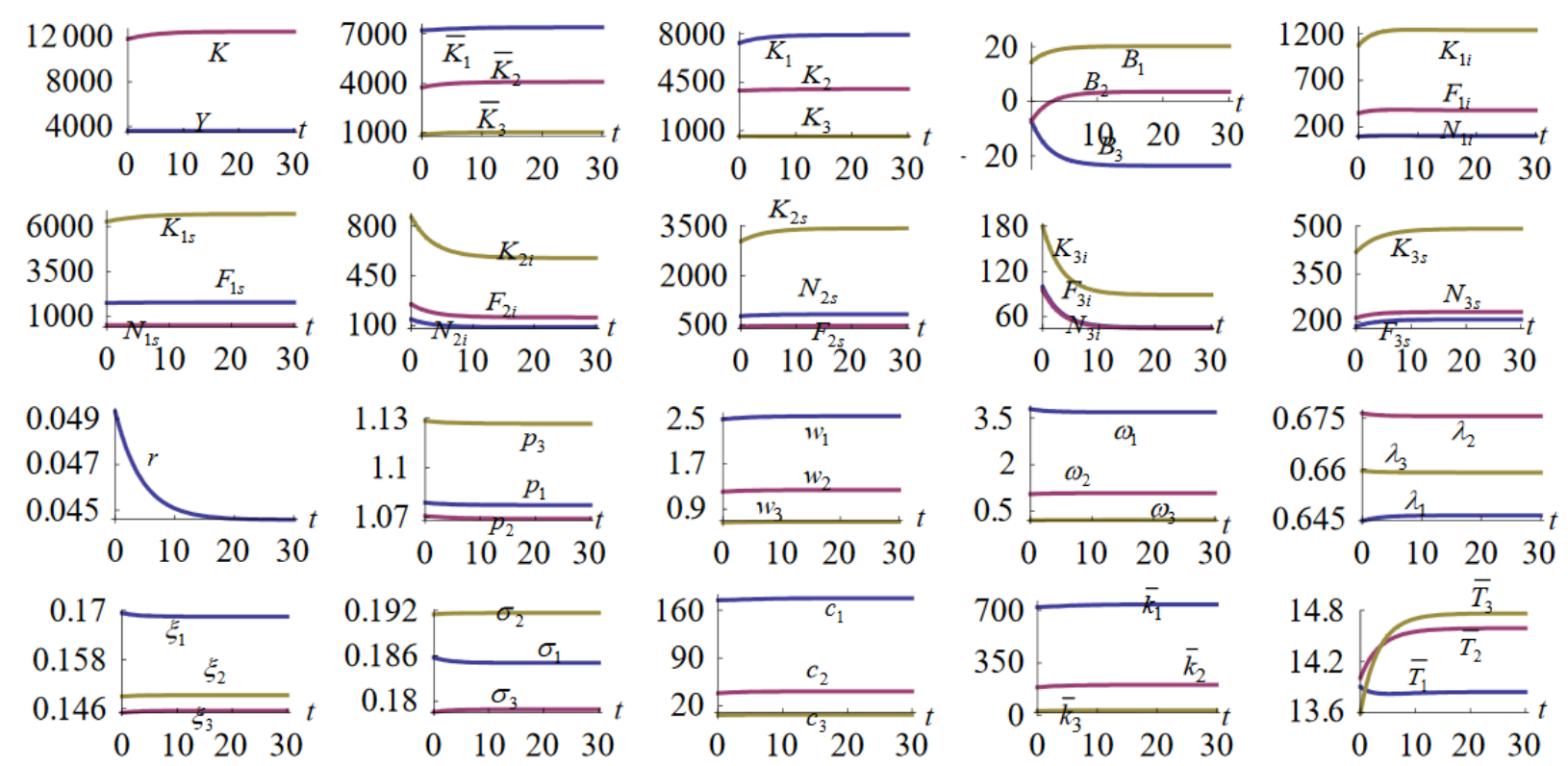

Figure 1. The Motion of the Economic System.

The system has a stable equilibrium and the equilibrium point is listed as follows:

$Y=3615, K=12362, r=0.0458$,

$$
\begin{aligned}
& \left(\begin{array}{l}
Y_{1} \\
Y_{2} \\
Y_{3}
\end{array}\right)=\left(\begin{array}{l}
2312 \\
1027 \\
276
\end{array}\right),\left(\begin{array}{l}
\bar{K}_{1} \\
\bar{K}_{2} \\
\bar{K}_{3}
\end{array}\right)=\left(\begin{array}{l}
7264 \\
4069 \\
1029
\end{array}\right),\left(\begin{array}{l}
K_{1} \\
K_{2} \\
K_{3}
\end{array}\right)=\left(\begin{array}{c}
7878 \\
3916 \\
568
\end{array}\right),\left(\begin{array}{l}
B_{1} \\
B_{2} \\
B_{3}
\end{array}\right)=\left(\begin{array}{c}
-28 \\
7 \\
21
\end{array}\right), \\
& \left(\begin{array}{l}
p_{1} \\
p_{2} \\
p_{3}
\end{array}\right)=\left(\begin{array}{l}
1.08 \\
1.07 \\
1.23
\end{array}\right),\left(\begin{array}{l}
w_{1} \\
w_{2} \\
w_{3}
\end{array}\right)=\left(\begin{array}{l}
2.52 \\
1.23 \\
0.67
\end{array}\right),\left(\begin{array}{l}
F_{1 i} \\
F_{2 i} \\
F_{3 i}
\end{array}\right)=\left(\begin{array}{c}
422 \\
150 \\
43
\end{array}\right),\left(\begin{array}{l}
F_{1 s} \\
F_{2 s} \\
F_{3 s}
\end{array}\right)=\left(\begin{array}{c}
1754 \\
820 \\
2017
\end{array}\right), \\
& \left(\begin{array}{l}
N_{1 i} \\
N_{2 i} \\
N_{3 i}
\end{array}\right)=\left(\begin{array}{c}
115.4 \\
84 \\
44.2
\end{array}\right),\left(\begin{array}{l}
N_{1 s} \\
N_{2 s} \\
N_{3 s}
\end{array}\right)=\left(\begin{array}{l}
501.8 \\
478.3 \\
231.7
\end{array}\right),\left(\begin{array}{l}
K_{1 i} \\
K_{2 i} \\
K_{3 i}
\end{array}\right)=\left(\begin{array}{c}
1365.9 \\
540.9 \\
84.2
\end{array}\right),\left(\begin{array}{l}
K_{1 s} \\
K_{2 s} \\
K_{3 s}
\end{array}\right)=\left(\begin{array}{l}
6511.8 \\
3375.5 \\
483.4
\end{array}\right), \\
& \left(\begin{array}{l}
\tilde{k}_{1} \\
\tilde{k}_{2} \\
\tilde{k}_{3}
\end{array}\right)=\left(\begin{array}{l}
3.53 \\
0.99 \\
0.17
\end{array}\right),\left(\begin{array}{l}
\omega_{1} \\
\omega_{2} \\
\omega_{3}
\end{array}\right)=\left(\begin{array}{l}
3.68 \\
1.08 \\
0.22
\end{array}\right),\left(\begin{array}{l}
\lambda_{1} \\
\lambda_{2} \\
\lambda_{3}
\end{array}\right)=\left(\begin{array}{c}
0.65 \\
0.68 \\
0.66
\end{array}\right),\left(\begin{array}{l}
\xi_{1} \\
\xi_{2} \\
\xi_{3}
\end{array}\right)=\left(\begin{array}{l}
0.17 \\
0.15 \\
0.15
\end{array}\right), \\
& \left(\begin{array}{l}
\sigma_{1} \\
\sigma_{2} \\
\sigma_{3}
\end{array}\right)=\left(\begin{array}{l}
0.19 \\
0.18 \\
0.19
\end{array}\right),\left(\begin{array}{l}
\bar{k}_{1} \\
\bar{k}_{2} \\
\bar{k}_{3}
\end{array}\right)=\left(\begin{array}{l}
726.4 \\
203.5 \\
34.3
\end{array}\right),\left(\begin{array}{l}
c_{1} \\
c_{2} \\
c_{3}
\end{array}\right)=\left(\begin{array}{c}
175.4 \\
41 \\
6.9
\end{array}\right),\left(\begin{array}{l}
\bar{T}_{1} \\
\bar{T}_{2} \\
\bar{T}_{3}
\end{array}\right)=\left(\begin{array}{l}
13.7 \\
14.6 \\
14.8
\end{array}\right) .
\end{aligned}
$$

The three eigenvalues are as follows:

$-0.37,-0.33,-0.24$.

The equilibrium point is stable. 


\section{Comparative Dynamic Analysis}

The previous section simulated the global economy. It shows how the system over time from the initial state to the equilibrium point. The simulation was conducted when all the parameters are time-independent. This section shows existence of business cycles when economies receive different exogenously periodic perturbations. We apply a variable $\bar{\Delta} x_{j}(t)$ to stand for the change rate of the variable, $x_{j}(t)$, in percentage due to changes in a parameter.

\subsection{Weights Given to Relative Wealth in Determining Social Status Periodically Oscillate}

We first show how global economy is affected if the weights given to relative wealth in determining social status are exogenously periodically changed as follows:

$\omega_{k 1}(t)=\omega_{k 2}(t)=\omega_{k 3}(t)=1+0.05 \sin (t)$.

The weights that the three nations value their relative economic positions in determining social status oscillate over time. The simulation result is given in Figure 2. We see that all the variables change periodically over time.
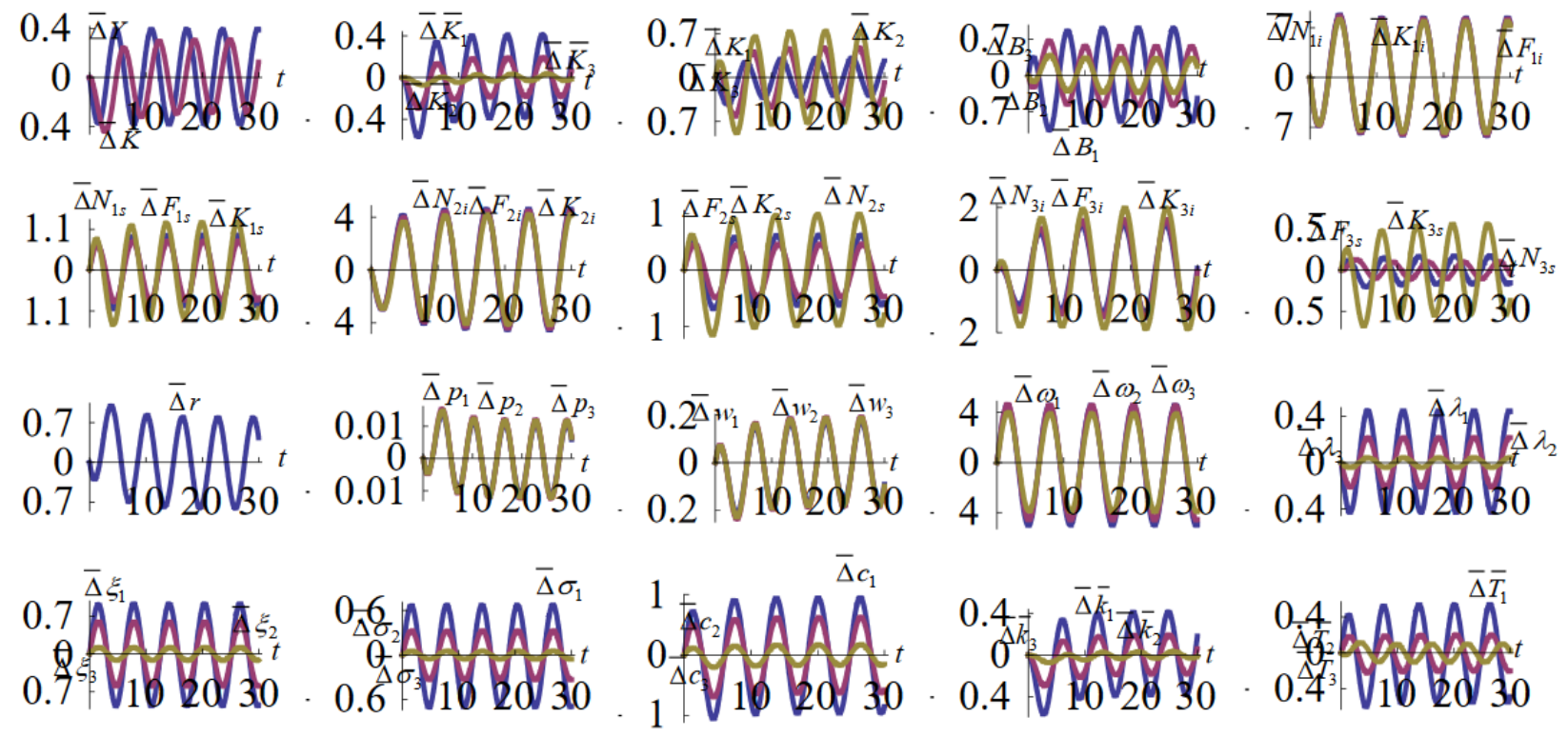

Figure 2. Weights Given to the Relative Wealth in Social Status Periodically Oscillate.

\subsection{The Strengths That the Propensities to Save Are Affected by Social Status Oscillate}

We now show another case that the global economy experiences business cycles. The strengths that the propensities to save are affected by social status exogenously periodically oscillate as follows 
$\tilde{\lambda}_{10}(t)=\tilde{\lambda}_{20}(t)=\tilde{\lambda}_{30}(t)=0.1+0.01 \sin (t)$.

The simulation result is given in Figure 3.
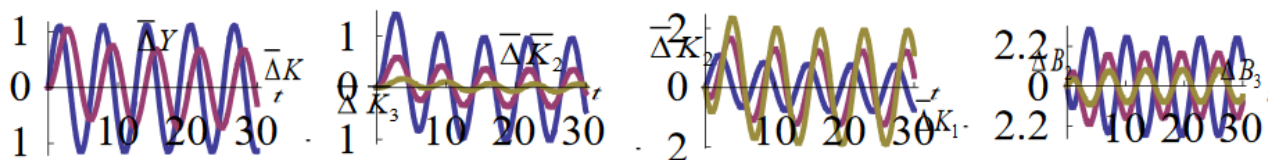

20 . 2

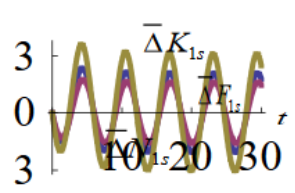

$7^{\bar{\Delta}} F_{2 i} \bar{\Delta} K_{2 i} \bar{\Delta} N_{2 i}$
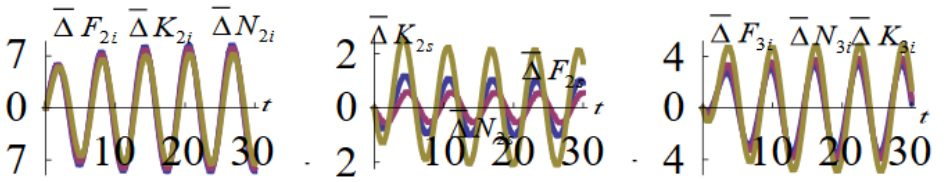

$1.5 \bar{\Delta}_{3 s}^{\bar{\Delta}}$
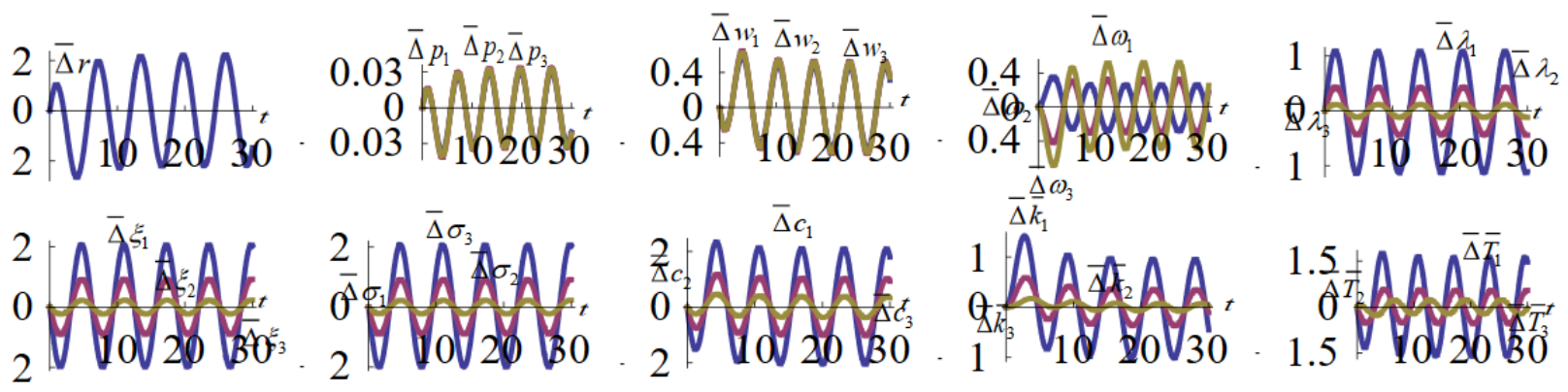

Figure 3. The Strengths the Propensities to Save are Affected by Social Status Oscillate.

\subsection{Country 1's Social Status Oscillates}

We now study a case that country 1's social status oscillates as follows:

$\omega_{01}(t)=0.15+0.01 \sin (t)$.

The simulation result is given in Figure 4. Different from the previous two cases, this time only one country experiences exogenous shocks. We see that country 1's macroeconomic variables and microeconomic variables oscillate greatly, while the other two economies' some of the macroeconomic variables change greatly but the microeconomic variables are affected slightly. 

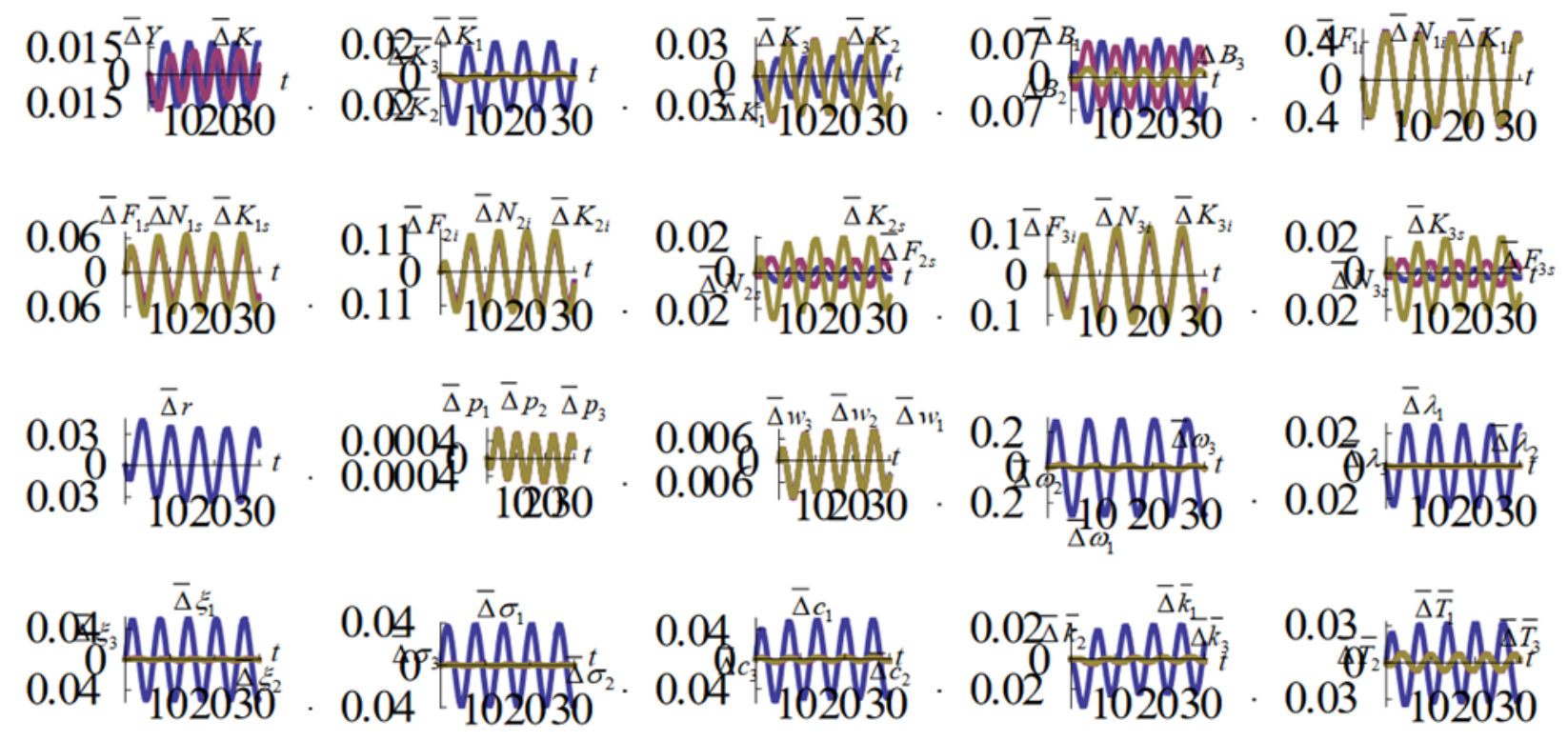

Figure 4. Country 1's Social Status Oscillates.

\subsection{Country 1's Human Capital Oscillates}

Human capital is changed either exogenously or endogenously in economic theory. This study assume human capital exogenous. Nevertheless, our model is robust enough to analyze any timedependent exogenous changes in human capital. We now examine a case that country 1's human capital oscillate as follows:

$h_{1}(t)=6+0.05 \sin (t)$

The simulation result is given in Figure 5. We see that all the variables in the global system are affected by country 1's changes in human capital. The capital goods sectors and oscillate in similarly among the economies. The wage rates change similarly among the economies but in the opposite direction to the rate of interest. 


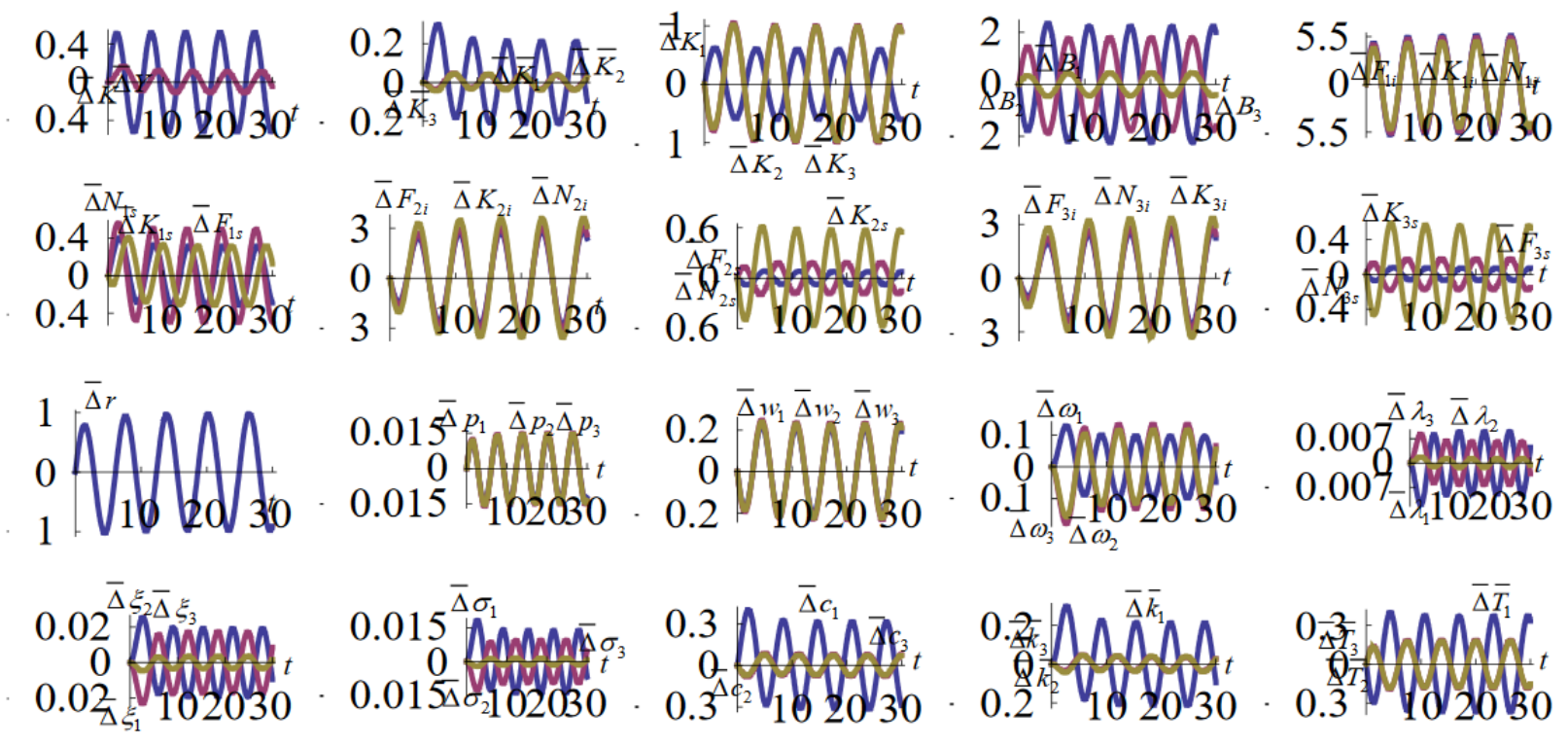

Figure 5. Country 1's Human Capital Being Enhanced.

\section{Conclusions}

This paper extended Zhang's global economic growth model with endogenous social status, endogenous preferences, and wealth accumulation by allowing all constant parameters to be timedependent parameters (Zhang, 2017). The basic model is built on the the Solow model (Solow, 1956), the Uzawa two-sector model (Uzawa, 1961), and the Oniki-Uzawa trade model (Oniki \& Uzawa, 1965), and some ideas in the literature of economic growth with endogenous growth. This model introduced various time-dependent exogenous shocks to Zhang's model. We simulated a few cases to demonstrate existence of business cycles with different exogenous periodic shocks. In the literature of real business cycles, there are a few models built on microeconomic foundation with complicated interdependence among many variables. The unique contribution is to identify real business cycles in the neoclassical growth model with endogenous preference built on microeconomic foundation. It should be mentioned that as Zhang's original analytical framework is general, it is possible to generalize and extend the model in different aspects. 


\section{References}

Chang, W. Y. (2006). Relative wealth, consumption taxation, and economic growth. Journal of Economics, 88(2), 103-129.

Chen, H. J., \& Guo, J. T. (2011). Money, Social Status and Endogenous Growth in a Generalized Cash-In-Advance Model. Pacific Economic Review, 16(3), 267-284.

Chiarella, C., \& Flaschel, P. (2000). The Dynamics of Keynesian Monetary Growth: Macro Foundations. Cambridge: Cambridge University Press.

Clemens, C. (2004). Status, risk-taking and intertemporal substitution in an endogenous growth model. Journal of Economics, 83(2), 103-123.

Cole, H.L., Mailath, G.J., \& Postlewaite, A. (1992). Social norms, savings behavior, and growth. Journal of Political Economy, 100(6), 1092-1025.

Corneo, G., \& O. Jeanne (2001). On relative wealth effects and long-run growth. Research in Economics, 55(4), 349-358.

Duesenberry, J. (1949). Income, Saving and the Theory of Consumer Behavior. Cambridge: Harvard University Press.

Fershtman, C., Murphy, K.M., \& Weiss, Y. (1996). Social status, education and growth. Journal of Political Economy, 104(1), 108-132.

Fisher, W. H., \& Hof, F. X. (2005). Status seeking in the small open economy. Journal of Macroeconomics, 27(2), 209-232.

Frank, R. H. (1985). Choosing the right pond: Human behavior and the quest for status. Oxford University Press.

Frank, R. H. (2001). Luxury fever: Why money fails to satisfy in an era of excess. Simon and Schuster.

Gandolfo, G. (2005). Economic Dynamics. Berlin: Springer.

Ikeda, S., \& Ono, Y. (1992). Macroeconomic dynamics in a multi-country economy - A dynamic optimization approach. International Economic Review, 33(3), 629-644.

Konrad, K. (1992). Wealth seeking reconsidered. Journal of Economic Behavior and Organization, $18(2), 215-227$.

Kurz, M. (1968). Optimal economic growth and wealth effects. International Economic Review, 9(3), 348-357.

Lorenz, H. W. (1993). Nonlinear Dynamic Economics and Chaotic Motion. Berlin: Springer-Verlag.

Oniki, H., \& Uzawa, H. (1965). Patterns of trade and investment in a dynamic model of international trade. Review of Economic Studies, 32(1), 15-38. 
Puu, T. (2011). Nonlinear Economic Dynamics. Berlin: Springer.

Rauscher, M. (1997). Conspicuous consumption, economic growth, and taxation. Journal of Economics, 66(1), 35-42.

Rege, M. (2008). Why do people care about social status? Journal of Economic Behavior \& Organization, 66(2), 233-242.

Shone, R. (2002). Economic Dynamics: Phase diagrams and their economic application. Cambridge University Press.

Solow, R. (1956). A contribution to the theory of growth. Quarterly Journal of Economics, 70(1), 65 94.

Uzawa, H. (1961). On a two-sector model of economic growth. Review of Economic Studies, 29(1), 47-70.

Veblen, T. (1899). The Theory of the Leisure Class. New York: Modern Library.

Zhang, W. B. (1991). Synergetic Economics. Springer-Verlag, Heidelberg.

Zhang, W. B. (2005). Differential Equations, Bifurcations, and Chaos in Economics. Singapore: World Scientific.

Zhang, W. B. (2006). Discrete Dynamical Systems, Bifurcations and Chaos in Economics. Amsterdam: Elsevier.

Zhang, W. B. (2017). Global social status, national spirits of capitalism, and economic development. Economics, 21(2), 53-75. 


\section{Appendix: Proving the Lemma}

We omit the time variable in the Appendix. Equations (3) and (5) imply

$$
z_{j} \equiv \frac{r+\delta_{j k}}{w_{j}}=\frac{N_{j m}}{\bar{\beta}_{j m} K_{j m}}, j=1, \ldots, J, m=i, s,
$$

where $\bar{\beta}_{j m} \equiv \beta_{j m} / \alpha_{j m}$. Inserting (A1) in (3) gives

$$
r=\alpha_{j r} z_{j}^{\beta j i}-\delta_{j k}, w_{j}=\alpha_{j} z_{j}^{-\alpha_{j i}}
$$

in which

$$
\alpha_{j r}=\alpha_{j i} \bar{\beta}_{j i}^{\beta_{j i}} A_{j i}, \quad \alpha_{j}=\frac{\beta_{j i} A_{j i}}{\bar{\beta}_{j i}^{\alpha_{j i}}}
$$

With (A2) we get

$$
r=\alpha_{j r} z_{j}^{\beta_{j i}}-\delta_{j k}=\alpha_{1 r} z_{1}^{\beta_{1 i}}-\delta_{1 k}, j=1, \ldots, J .
$$

The above equations give

$$
z_{j}\left(z_{1}\right)=\left(\frac{\alpha_{1 r} z_{1}^{\beta_{1 i}}+\delta_{j k}-\delta_{1 k}}{\alpha_{j r}}\right)^{1 / \beta_{j i}}, j=2, \ldots, J
$$

Equations (4) and (5) imply

$$
p_{j}\left(z_{1}\right)=\frac{\bar{\beta}_{j s}^{\alpha_{j s}} z_{j}^{\alpha_{j s}} w_{j}}{\beta_{j s} A_{j s}}
$$

The definitions of $\bar{y}_{j}$ imply

$$
\bar{y}_{j}=(1+r) \bar{k}_{j}+h_{j} T_{0} w_{j} .
$$


Inserting $p_{j} c_{j}=\xi_{j} \bar{y}_{j}$ in (23) gives

$$
\xi_{j} \bar{N}_{j} \bar{y}_{j}=p_{j} F_{j s}
$$

Insert (A5) in (A6) gives

$$
N_{j s}=g_{j} \xi_{j} \bar{k}_{j}+\xi_{j} \bar{g}_{j}
$$

in which we applyw $w_{j} N_{j s}=\beta_{j s} p_{j} F_{j s}$ and

$g_{j}\left(z_{1}\right) \equiv\left(\frac{1+r}{w_{j}}\right) \beta_{j s} \bar{N}_{j}, \quad \bar{g}_{j} \equiv \beta_{j s} h_{j} T_{0} \bar{N}_{j}$

Equations (A5) and (17) imply:

$$
\bar{T}_{j}=\frac{(1+r) \sigma_{j} \bar{k}_{j}}{h_{j} w_{j}}+\sigma_{j} T_{0}
$$

From (A8) we solve

$$
T_{j}=\left(1-\sigma_{j}\right) T_{0}-\frac{(1+r)}{h_{j} w_{j}} \sigma_{j} \bar{k}_{j}
$$

Equations (A9) and (1) give:

$$
N_{j}=\left(1-\sigma_{j}\right) R_{0 j}-R_{j} \sigma_{j} \bar{k}_{j}
$$

in which

$$
R_{0 j} \equiv h_{j} \bar{N}_{j} T_{0}, \quad R_{j} \equiv \frac{(1+r) h_{j} \bar{N}_{j}}{h_{j} w_{j}} .
$$

By (11) we get

$$
N_{j i}=N_{j}-N_{j s}
$$

By (A1) and (19), we obtain 


$$
\frac{N_{j i}}{z_{j} \bar{\beta}_{j i}}+\frac{N_{j s}}{Z_{j} \bar{\beta}_{j s}}=K_{j}
$$

From (A11) in (A12) we solve

$$
\tilde{\beta}_{j} N_{j}+\bar{\beta}_{j} N_{j s}=K_{j}
$$

in which

$$
\tilde{\beta}_{j} \equiv \frac{1}{z_{j} \bar{\beta}_{j i}}, \quad \bar{\beta}_{j} \equiv\left(\frac{1}{\bar{\beta}_{j s}}-\frac{1}{\bar{\beta}_{j i}}\right) \frac{1}{z_{j}} .
$$

Insert (A7) and (A10) in (A13)

$$
K_{j}=R_{k j} \bar{k}_{j}+\tilde{R}_{0 j}
$$

in which

$$
R_{k j} \equiv \bar{\beta}_{j} g_{j} \xi_{j}-R_{j} \sigma_{j} \tilde{\beta}_{j}, \tilde{R}_{0 j} \equiv\left(1-\sigma_{j}\right) \tilde{\beta}_{j} R_{0 j}+\bar{\beta}_{j} \xi_{j} \bar{g}_{j}
$$

Summing equations (A14) yields

$$
K=\sum_{j=1}^{J} R_{k j} \bar{k}_{j}+R_{0}
$$

in which

$$
R_{0} \equiv \sum_{j=1}^{J} \tilde{R}_{0 j}
$$

By (13) and (14) we get

$$
\bar{k}_{j}=\phi_{j}\left(K,\left\{\tilde{k}_{j}\right\}\right) \equiv \frac{K \tilde{k}_{j}}{\bar{N}}, j=2, \ldots, J
$$


Using

$$
\sum_{j=1}^{J} \tilde{k}_{j} \bar{N}_{j}=\frac{\bar{N}}{K} \sum_{j=1}^{J} \bar{k}_{j} \bar{N}_{j}=\bar{N}
$$

we solve:

$$
\tilde{k}_{1}=\phi_{j}\left(\left\{\tilde{k}_{j}\right\}, t\right) \equiv\left(\bar{N}-\sum_{j=2}^{J} \tilde{k}_{j} \bar{N}_{j}\right) \frac{1}{\bar{N}_{1}}
$$

We thus get:

$$
\bar{k}_{1}=\phi_{j}\left(K,\left\{\tilde{k}_{j}\right\}, t\right) \equiv \frac{K \tilde{k}_{1}}{\bar{N}}
$$

Inserting (A16) and (A18) in (A15) gives

$$
K\left(K,\left\{\tilde{k}_{j}\right\}, t\right)=\frac{K}{\bar{N}} \sum_{j=1}^{J} R_{k j} \tilde{k}_{j}+R_{0}
$$

By (A19) we get:

$$
K=\phi\left(z_{1},\left\{\tilde{k}_{j}\right\}, t\right) \equiv R_{0}\left(1-\frac{1}{\bar{N}} \sum_{j=1}^{J} R_{k j} \tilde{k}_{j}\right)^{-1}
$$

We thus confirmed the procedure in the Lemma. By the procedure in the Lemma, (23) and (18), we get:

$$
\begin{aligned}
& \dot{K}=\Lambda_{K}\left(z_{1},\left\{\tilde{k}_{j}\right\}, t\right) \equiv F-\sum_{j=1}^{J} \delta_{j k} K_{j}, \\
& \dot{\bar{k}}_{j}=\Lambda_{j}\left(z_{1},\left\{\tilde{k}_{j}\right\}, t\right) \equiv \lambda_{j} \bar{y}_{j}-\bar{k}_{j}, j=1, \ldots, J .
\end{aligned}
$$

Taking derivatives of (A16) in $t$, we get 


$$
\dot{\bar{k}}_{j}=\frac{\tilde{k}_{j}}{\bar{N}} \dot{K}+\frac{K}{\bar{N}} \dot{\tilde{k}}_{j}, j=2, \ldots, J
$$

From (A21) - (A23) we get

$$
\dot{\tilde{k}}_{j}=\Omega_{j}\left(z_{1},\left\{\tilde{k}_{j}\right\}, t\right) \equiv \frac{\Lambda_{j} \bar{N}}{K}-\frac{\tilde{k}_{j} \Lambda_{K}}{K}, j=2, \ldots, J
$$

Take derivatives of (A20) in time

$$
\dot{K}=\frac{\partial \phi}{\partial z_{1}} \dot{z}_{1}+\frac{\partial \phi}{\partial t}+\sum_{j=2}^{J} \Omega_{j} \frac{\partial \phi}{\partial \widetilde{k}_{j}^{\prime}}
$$

in which we use (A19). From (A19) and (A25), we get

$$
\dot{z}_{1}=\Omega_{1}\left(z_{1},\left\{\tilde{k}_{j}\right\} . t\right) \equiv\left(\Lambda_{K}-\frac{\partial \phi}{\partial t}-\sum_{j=2}^{J} \Omega_{j} \frac{\partial \phi}{\partial \tilde{k}_{j}}\right)\left(\frac{\partial \phi}{\partial z_{1}}\right)^{-1}
$$

In summary, we proved the Lemma. 